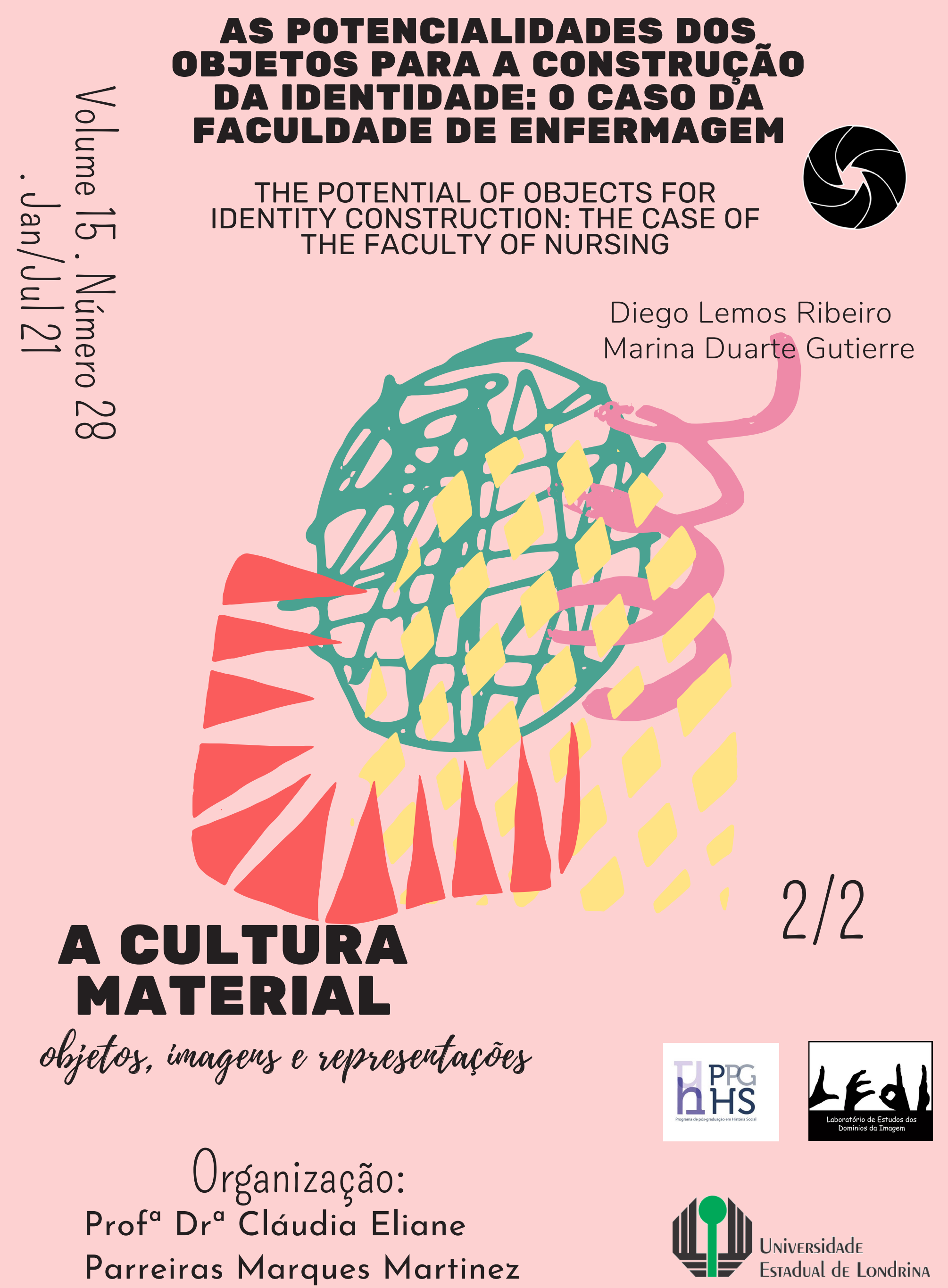




\section{AS POTENCIALIDADES DOS OBJETOS PARA A CONSTRUÇÃO DA IDENTIDADE: O CASO DA FACULDADE DE ENFERMAGEM}

\section{THE POTENTIAL OF THE OBJECTS FOR THE CONSTRUCTION OF THE IDENTITY: THE CASE OF SCHOOL OF NURSING}

\author{
Diego Lemos Ribeiro ${ }^{1}$ \\ Marina Duarte Gutierre ${ }^{2}$
}

Resumo: O trabalho apresentado investiga a vontade de memória da Faculdade de Enfermagem da Universidade Federal de Pelotas, demonstrada através do ato de selecionar objetos que representam seu fazer profissional e sua caminhada institucional. A seleção de objetos implica na compreensão de conceitos relacionados à coleção e no trajeto até essa definição. Além disso, refletirá sobre a potencialidade que os objetos preservados têm - ou podem adquirir- na construção da memória e identidade do grupo estudado, e como esse potencial é afetado pela forma como são exibidos.

Palavras-chave: Memória; Identidade; Coleção; Faculdade de Enfermagem.

\begin{abstract}
The presented paper investigate the memory desire of School of Nursing from the Federal University of Pelotas, demonstrated through the act of selecting objects that represent their professional and institutional journey. The selection of objects has implications for the understanding of concepts related to the collection and the path towards this definition. In addition, it will reflect on the potential that preserved objects have - or can acquire, in construction of the memory and identity of the studied group, and how this potential is affected the way they are displayed.
\end{abstract}

Keywords: Memory; Identity; Collection; School of Nursing.
1 Doutor em Arqueologia pela Universidade de São Paulo (MAE-USP), Professor Adjunto da Universidade Federal de Pelotas, Pelotas, Rio Grande do Sul. dlrmuseologo@yahoo.com. br. ORCID ID: https:// orcid.org/0000-00022433-4828.

${ }^{2}$ Mestre em Memória Social e Patrimônio Cultural pela Universidade Federal de Pelotas, Museóloga do Museu Carlos Nobre de Guaíba, Rio Grande do Sul. marinagutierre@yahoo.com. br. ORCID ID https:// orcid.org/0000-00034267-5164. 


\section{INTRODUÇÃO}

O objetivo da discussão que aqui se apresenta é refletir sobre as potencialidades que as coleções de objetos podem alcançar na construção da memória e da identidade de determinado grupo social ${ }^{3}$. Neste artigo, pesquisamos essa relação através do caso da Faculdade de Enfermagem (FEn) da Universidade Federal de Pelotas (UFPel) no Rio Grande do Sul.

A FEn foi fundada em 1976 e ao longo de sua história buscou formas de retomar e celebrar sua jornada, principalmente em atividades alusivas às comemorações de seus 30 anos de fundação. Tais iniciativas proporcionaram a coleção de objetos representativos para a história institucional, profissional e científica da unidade, pois boa parte dos artefatos e documentos coletados nessa ocasião foram doados à Faculdade.

Ao longo deste artigo abordar-se-á o movimento traçado pela Faculdade de Enfermagem na busca por sua construção memorial, uma vez que, ao compreender esse processo, será possível perceber a relação desenvolvida com sua cultura material e analisar a forma como a preservação dos objetos pode transformar a potencialidade inerente a esse processo em realidade, para constituição de sua memória e identidade.

O Curso de Enfermagem e Obstetrícia (FEO) foi criado no ano de 1976 e em 1980 (Cursos e Faculdades, 2015, s/p) foi reconhecido pelo MEC, em 1989 ganhou status de faculdade, passando a contar com estrutura própria. Apesar do reconhecimento enquanto Faculdade, fisicamente a FEn manteve-se localizada no chamado Campus da Saúde, situado à Avenida Duque de Caxias no Bairro Fragata, até 2006, quando se mudou, provisoriamente, para a rua XV de Novembro, conforme reportagem veiculada no jornal Diário Popular:

[...] com a expansão verificada, o espaço físico, que durante algum tempo se mostrou suficiente, esgotou sua capacidade, dificultando o exercício das atividades acadêmicas. $O$ problema se agravou com a intervenção realizada no pavimento térreo do prédio (módulo B do Campus da Saúde), cujas obras exigiram a desocupação da parte superior do imóvel. Começava então uma grande mobilização da comunidade da FEO, no sentido de obter uma solução que restabelecesse as plenas condições ao processo ensino-aprendizagem. Sensível ao problema, a Administração Superior da Universidade destinou, em caráter provisório, o amplo sobrado localizado na rua Quinze de Novembro, 209, onde funcionou a Faculdade de Arquitetura e Urbanismo. (Diário Popular,16.08.2007)

A FEn permaneceu nesse endereço por cerca de dois anos. A mudança se deu em função do crescimento dos cursos da área da saúde, de forma que o Campus já não suportava as duas Faculdades, a de Medicina e a de Enfermagem. A busca por um local próprio para a FEn tornou-se uma das prioridades da unidade, podendo ser percebido no discurso dos professores e através do material produzido para a exposição dos 30
${ }^{3}$ Cabe ressaltar que este artigo é um produto da dissertação apresentada no Programa de Pós Graduação em Memória Social e Patrimônio Cultural, da Universidade Federal de Pelotas, defendida em 2016. 
anos da Unidade. Em 2010 a FEn se mudou definitivamente para o Campus Anglo ${ }^{4}$. Os movimentos de mudanças, rupturas, e mesmo traumas, com efeito, podem estimular a vontade de memória de determinado grupo - não à toa as coleções, por seu caráter mais duradouro, são utilizadas para ancorar determinado sentimento de pertencimento do grupo, com vistas a oferecer alguma estabilidade frente às mudanças.

Antes de aprofundar o olhar sobre a relação da FEn com sua cultura material, se faz necessário traçar algumas questões relativas ao conceito de identidade. Para Manuel Castells (2003) a identidade corresponde à fonte de significados e experiências de um povo. No tocante aos atores sociais, o autor considera a identidade como o processo de construção do significado com base no atributo cultural, ressaltando que, para um dado indivíduo ou ator coletivo, pode haver identidades múltiplas, constituindo fontes de significados para os atores, por eles organizadas, mas construídas através de um processo de individualização. Castells (2003) ressalta ainda que as identidades podem ser formadas a partir de instituições dominantes, mas apenas assumem essa condição no caso de os atores sociais a interiorizarem, constituindo, assim, seu significado.

Para Pollak (2006), a construção da identidade ocorre, essencialmente, através de três elementos, quais sejam: a unidade física; o sentimento de fronteiras individuais e mesmo coletivas; a continuidade no tempo e a unidade de coerência, ou seja, os diversos elementos formadores de um indivíduo são unificados. O autor conclui, portanto, que a memória é um elemento constituinte da identidade, tanto individual quanto coletiva, tendo em vista que é, também, um componente no sentimento de continuidade e de coerência de uma pessoa ou de um grupo, bem como de sua reconstrução.

É necessário destacar que o sentimento de continuidade, coerência e aceitabilidade são negociados no interior de um esquema comunicativo, em que símbolos e signos são agenciados. Em outros termos, a construção da imagem de identidade não se consubstancia ao natural, alheia ao indivíduo, ao grupo, ao tempo e ao espaço. Essa premissa nos leva a crer que a construção da identidade demanda certo nível de aceitabilidade, admissão e credibilidade, em negociação direta ou indireta com o outro (POLLAK, 2006). Dito de outro modo, o sentimento de identidade ganha seus contornos no momento em que as pessoas se apropriam, social e simbolicamente, dos seus referenciais de memória - no caso em exame neste artigo, a coleção formada pela FEn.

Nesse sentido, no que se refere à transmissão e consolidação da identidade de determinado grupo, Candau (2012) lembra que, além da escrita, outras formas menos tradicionais são, também, bastante eficientes. No caso de identidades familiares o desejo de continuidade pode se manifestar através da preservação de variados suportes como fotografias, antigos objetos, entre outros. É possível identificar uma vontade de pertencimento e continuidade de determinada identidade. Já no que se relaciona aos grupos
4 A Universidade Federal de Pelotas foi fundada em 1969. No ano de 2009, o antigo Frigorífico Anglo, após grande reforma, foi destinado a abrigar a Reitoria dessa instituição de ensino, bem como, 27 cursos de graduação e pós-graduação, incluindo a Faculdade de Enfermagem. 
profissionais, o autor considera que esses "valorizam os comportamentos adequados e reprimem os demais a fim de produzir uma memória adequada à reprodução de saberes e fazeres e à manutenção de uma identidade da profissão" (CANDAU, 2012, p. 118). Entretanto, a identidade profissional, de acordo com o autor, não se encerra no desenvolvimento das habilidades técnicas, uma vez que, para além delas, a identidade, na maioria das vezes, se inscreve nos corpos mesmos dos indivíduos.

Dessa forma, é possível perceber a relevância da construção de uma memória profissional, visualizando, nesse estudo, essa compreensão em uma unidade específica da Universidade Federal de Pelotas. A coleção formada por esse grupo não traduz, somente, um arranjo de objetos inseridos em determinado local; mais do que isto, consubstancia um estímulo de criar determinada imagem de si, na qual os integrantes do grupo possam se ver refletidos. Assim, as materialidades reunidas em caixas, armários, salas ou mesmo postos ao olhar, adquirem novos significados e funções; há, neste movimento, uma intencionalidade representacional que extrapola o sentido original dessas reminiscências, passando a produzir imagens sobre os saberes, trajetórias, anseios, conquistas e comportamentos daquele coletivo.

Ainda no que se refere à memória, interessa observar que parte dos objetos também são compostos de documentos institucionais propriamente ditos, que aludem ao ritual burocrático das instituições. De acordo com Rueda, Freitas e Valls (2011), salvaguardar documentos relativos a tomadas de decisão faz parte da rotina de qualquer instituição, caracterizando-se, então, como elementos constitutivos de uma memória institucional. Ainda para os autores, a memória institucional se caracteriza como importante ferramenta para seu desenvolvimento e comunicação com a sociedade em que está inserida, tornando-se, dessa maneira, seu elemento aglutinador, identitário.

Assim, é possível supor que as instituições, através de "sistematização de uma história e de uma memória, produzindo a partir desse movimento a sua própria legitimação” (RIBEIRO E BARBOSA, 2005, p. 106), buscam, de acordo com os autores, elementos capazes de reforçar o sentimento de pertencimento, procurando "manter a coesão interna" (RIBEIRO E BARBOSA, p. 106). No caso da FEn, é possível transpor os aspectos de pertencimento e legitimação para o acervo reunido, uma vez que os objetos da cultura material mobilizam, nos alunos, professores e servidores, o sentimento de pertencimento e de construção desta instituição. Em certa medida, a formação dessa coleção funciona como uma sorte de gramática pela qual se pretende narrar a trajetória institucional. Isto feito, e na medida em que é incorporado e aceito pelos interlocutores, incrementa-se o potencial aglutinador dessas referências.

É possível perceber, também, que a vontade de memória da FEn está representada, principalmente, pelas comemorações e pela preservação de seus objetos. Dessa 
forma, entende-se que "consagrando o universalismo dos valores de uma comunidade, as comemorações buscam, nessa "rememoração" de acontecimentos passados, significações diversas para uso do presente”. (SILVA, 2002, p. 432). Importa observar, por este prisma, que os objetos assumem novo status nesse jogo de rememoração: para além do sentido utilitário e burocrático, passam a mediar fundamental papel ao criarem liames com pessoas, lugares, relacionamentos e histórias a serem contadas.

Se faz necessário, portanto, relacionar Pierre Nora (1993, p. 13), quando afirma que determinadas ações, tais como a comemoração ou a criação de museus e arquivos, por exemplo, não são atividades naturais, de tal modo que "Sem vigilância comemorativa, a memória depressa os varreria. São bastiões sobre os quais se escora”. Nesse sentido, comemorações, objetos aparentemente obsoletos e banais, documentos institucionais, todos esses podem ser considerados lugares em que a memória se fixa, ao mesmo tempo em que tem a potência para criar novos nexos e novas malhas de conhecimento.

Assim, o desejo de comemoração e a preservação dos objetos podem caracterizar-se como os elementos sociotransmissores, postulado por Candau (2010). De acordo com o autor, esses elementos funcionam como os neurônios para o cérebro, ou seja, favorecem conexões. Ainda segundo o autor, os sociotransmissores podem ser todos os objetos ou comportamentos humanos, os quais auxiliam a estabilizar uma cadeia cognitiva entre dois ou mais indivíduos.

Sendo assim, é possível perceber, no caso da Faculdade de Enfermagem, que a busca pela construção da memória e da identidade se refletiu a partir do desejo pela comemoração desse curso. Através da valorização de seus elementos aglutinadores, ou seja, de suas retóricas holistas, conforme conceito de Candau (2012), seria possível, inclusive, imaginar a construção de uma memória forte compartilhada por esse grupo. Ao aprofundar as questões relacionadas à identidade, será possível compreender essa construção através do desejo de comemoração que será apresentado a seguir.

\section{1 - VONTADE DE MEMÓRIA: A COMEMORAÇÃO DOS 30 ANOS}

Percorrer, ainda que brevemente, o histórico de consolidação da FEn e os elementos que podem favorecer a construção da memória e da identidade de determinado grupo social, em especial do ponto de vista profissional, proporcionou subsídios necessários para compreender o processo memorial, através da comemoração, do qual a Faculdade de Enfermagem lançou mão para reforçar suas fronteiras identitárias.

No ano de 2006, houve a posse da nova diretoria da FEn. A diretora eleita, Profa. Luciane Kantorski, juntamente com os demais membros da diretoria, organizaram uma exposição comemorativa aos 30 anos da unidade. De acordo com a Profa. Luciane Kantorski:
5 [...] a "rememoração" [...] proporciona o sentimento da distância temporal; mas ela é a continuidade entre presente, passado recente, passado distante, que me permite remontar sem solução de continuidade do presente vivido até os acontecimentos mais recuados da minha infância. (SILVA, 2002, p. 428) 
[...] na ocasião de comemoração dos 30 anos da enfermagem alguns professores, servidores e egressos trouxeram alguns objetos pessoais como convites de formatura, fotografias, uniformes e juntamente com objetos que tínhamos guardados na Faculdade e que expressam a memória da mesma foi montado numa sala de professores um espaço de exposição. Em outras ocasiões de comemoração isso também ocorreu nos corredores e em outros espaços. (KANTORSKI, 2015, s/p) ${ }^{6}$

Através da pesquisa realizada para a elaboração da exposição dos 30 anos da FEn, os objetos, textos elaborados pelos professores, fotografias e documentos selecionados foram apresentados ao público, buscando contar a história da unidade.

A comemoração dos 30 anos da FEn ocorreu entre os dias 24 de agosto e 05 de setembro de 2006. Naquele momento, a Faculdade de Enfermagem ainda se localizava no chamado Campus da Saúde, situado na Avenida Duque de Caxias, bairro Fragata, no mesmo complexo educacional da Faculdade de Medicina.

$\mathrm{Na}$ ocasião, foi desenvolvido o projeto de extensão "A FEO 30 anos de existência e História: contribuindo com o cenário da qualidade de saúde em Pelotas e região”, em que alunos e professores participaram da pesquisa acerca da história da unidade. Dessa forma, foram localizados egressos e antigos professores para que emprestassem e/ou doassem material relativo à Faculdade de Enfermagem, como antigas togas, fotografias dos projetos desenvolvidos pela Faculdade, e das instalações. Já os objetos, seringas de vidro, antigas embalagens de gaze e algodão e o material para esterilizar os instrumentos hospitalares, foram preservados pela Unidade. Parte dos documentos e fotografias levantados para a exposição foram doados à FEn.

Dois anos após a comemoração, como já mencionado, a FEn instalou-se em sua sede definitiva. A diretoria da unidade preservou os objetos e os documentos selecionados para a exposição, que foram acondicionados de acordo com o espaço disponível na nova estrutura física.

A reunião desses objetos deve ser observada de forma densa, para além do mero acúmulo. Nesse ato, aparentemente singelo, há uma intenção deliberada de perpetuar essas reminiscências, de inscrevê-las em um novo arranjo semântico. Há, portanto, não apenas um deslocamento físico dos objetos (do privado à instituição, de uma sala à outra), mas, sobretudo, um deslocamento de sentidos ao dar-lhes nova funcionalidade e significação. Veja: convites de formatura, que outrora serviam para invitar amigos e familiares, possivelmente do círculo íntimo da pessoa, nesse contexto, agora coletivo, ganham outra finalidade; uniformes, que em outro momento lhes serviam para cobrir o corpo, e de certa forma dar unidade aos sujeitos do grupo, nesse arranjo são mais úteis para fazer refletir sobre a trajetória da Faculdade. O mesmo se poderia dizer sobre objetos aparentemente banais, que já são obsoletos para serem usados nas atividades para os quais foram adquiridos, mas que, atualmente, registram uma determinada memória institucional.

\footnotetext{
${ }^{6}$ As entrevistas com as Professoras da FEn ocorreram por meio de questionário e são importante fonte para a elaboração desta pesquisa. A entrevista com a Professora Luciane Kantorski ocorreu no ano de 2016.
} 
Ao analisar os objetos, foi possível perceber que estes apresentam três níveis de cuidado e extroversão. Optou-se, portanto, por analisá-los através desses níveis, sendo o primeiro o mais acessível, o segundo visível apenas ao público frequentador da FEn, mas com acesso físico restrito, e o terceiro caracterizado pela dificuldade maior ao acesso.

No primeiro nível estão os objetos dispostos num antigo armário de laboratório, localizado em um dos corredores da unidade. É o mais acessível dos três, uma vez que está no caminho percorrido diariamente por alunos, professores e servidores. Os objetos encontrados no armário fazem referência ao "Curso de Enfermagem e Obstetrícia" - antes de ganhar status de faculdade -, aos prêmios, às homenagens e publicações relativas ao curso. Relacionam-se, portanto, à abordagem histórica e ao pioneirismo desse grupo. Poucos materiais referem-se às antigas práticas da enfermagem, representados pela seringa e os copos de vidro. Salienta-se que o móvel onde se encontram esses objetos apresenta dimensões pequenas (cerca de 1,40m de altura por $1 \mathrm{~m}$ de largura), o que inviabilizaria a possibilidade de apresentar objetos maiores. Apesar disso, percebe-se que a maioria desses artefatos se relaciona mais à memória institucional do que à memória profissional ou, até mesmo, às práticas de ensino. Há que se referenciar, ainda, que, de acordo com a Prof ${ }^{a}$. Luciane Kantorski, em entrevista, havia esse armário inutilizado, imagem 01, remanescente de um antigo laboratório. Optou-se, então por expor nele alguns dos objetos do histórico da FEn, uma vez que não apresentam estrutura física para manter um memorial ou pequeno museu.

Por outro lado, apesar da pequena dimensão, deve-se analisar esse fenômeno não por sua característica física (o tamanho do armário), mas por sua potência simbólica que se projeta para fora do armário; por sua capacidade de criar imagens, imaginações, sobre o lugar que esses objetos ocupam dentro da trajetória da Curso; ao mesmo tempo, em um movimento pendular, por permitir que as pessoas que o observam se insiram nessa memória. Por outros termos, pode-se imaginar que esse singelo abre a possibilidade de criar agenciamentos entre as memórias institucional e individual, além de colocar em jogo os processos de aceitabilidade, admissão e credibilidade que engendram a constituição identitária da FEn. 


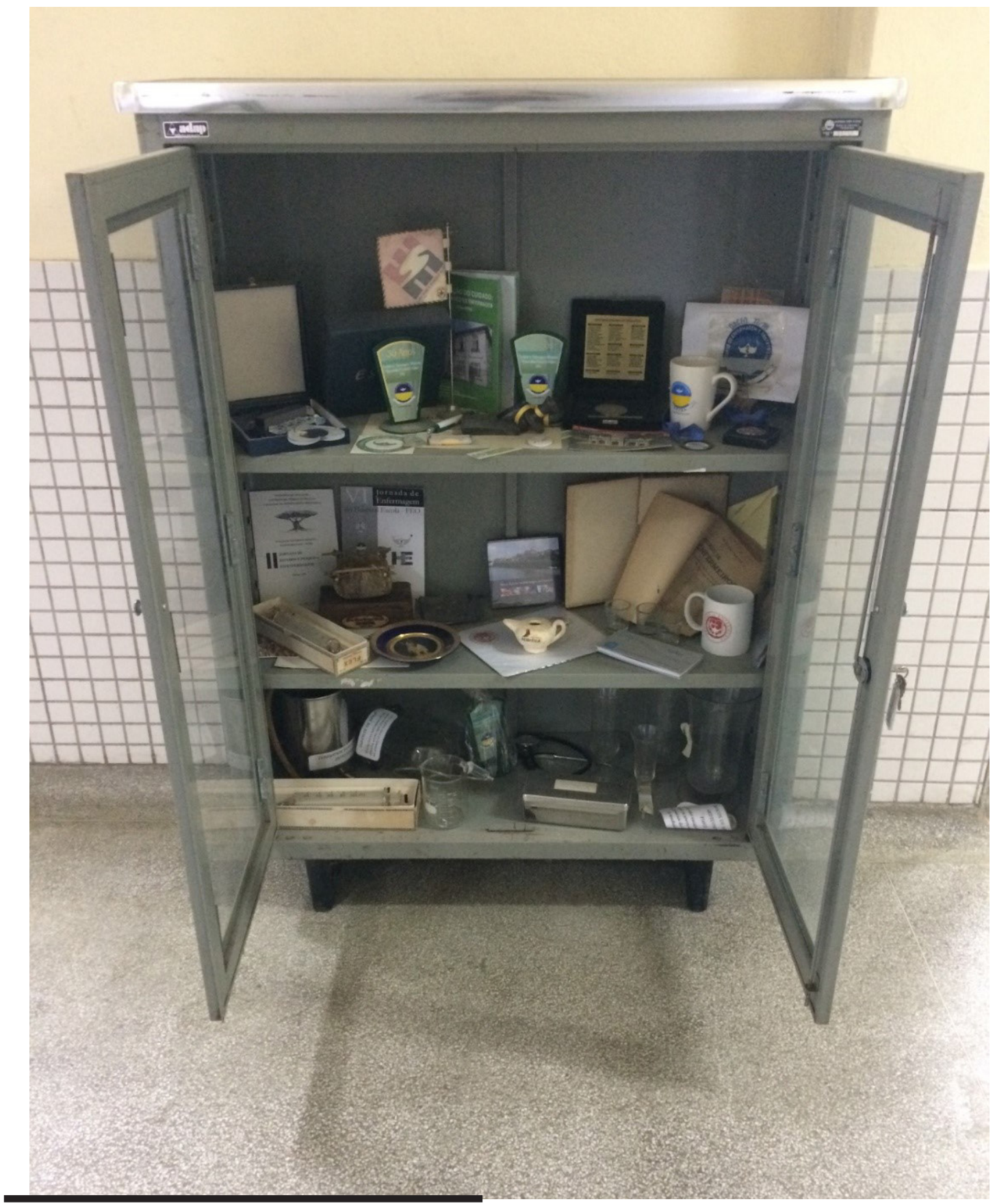

Imagem 1 - Armário objetos nível 1. Fonte: Imagem produzida pelos autores, 2016.

O segundo nível dos objetos é representado pelos documentos pesquisados e elaborados em função da comemoração dos 30 anos da unidade. O Colegiado da então Faculdade de Enfermagem e Obstetrícia doou os documentos que mantinha em sua guarda, tais como os livros-ata, entre os anos de 1977 e 1990; livros de registros de atividade, nos quais os professores e alunos relatavam as rotinas desenvolvidas nos estágios realizados nos hospitais; pastas contendo fotografias dos projetos de extensão desenvolvidos pela unidade; além do primeiro manual de Métodos e Técnicas, elaborado pelas professoras da FEn, de fichas funcionais, e de parte da documentação para a elaboração 
das cerimonias de formatura.

Houve cuidado em guardá-los e preservá-los para que fossem utilizados em outros momentos de comemoração, como ocorreu nos 35 anos da unidade. A documentação pesquisada encontra-se em duas caixas localizadas em um grande armário no laboratório de procedimentos na unidade - imagem 02. Portanto, os documentos administrativos dividem espaço com material hospitalar e de uso rotineiro para a realização das aulas práticas que ocorrem naquele local, não sendo o mais adequado para sua salvaguarda.

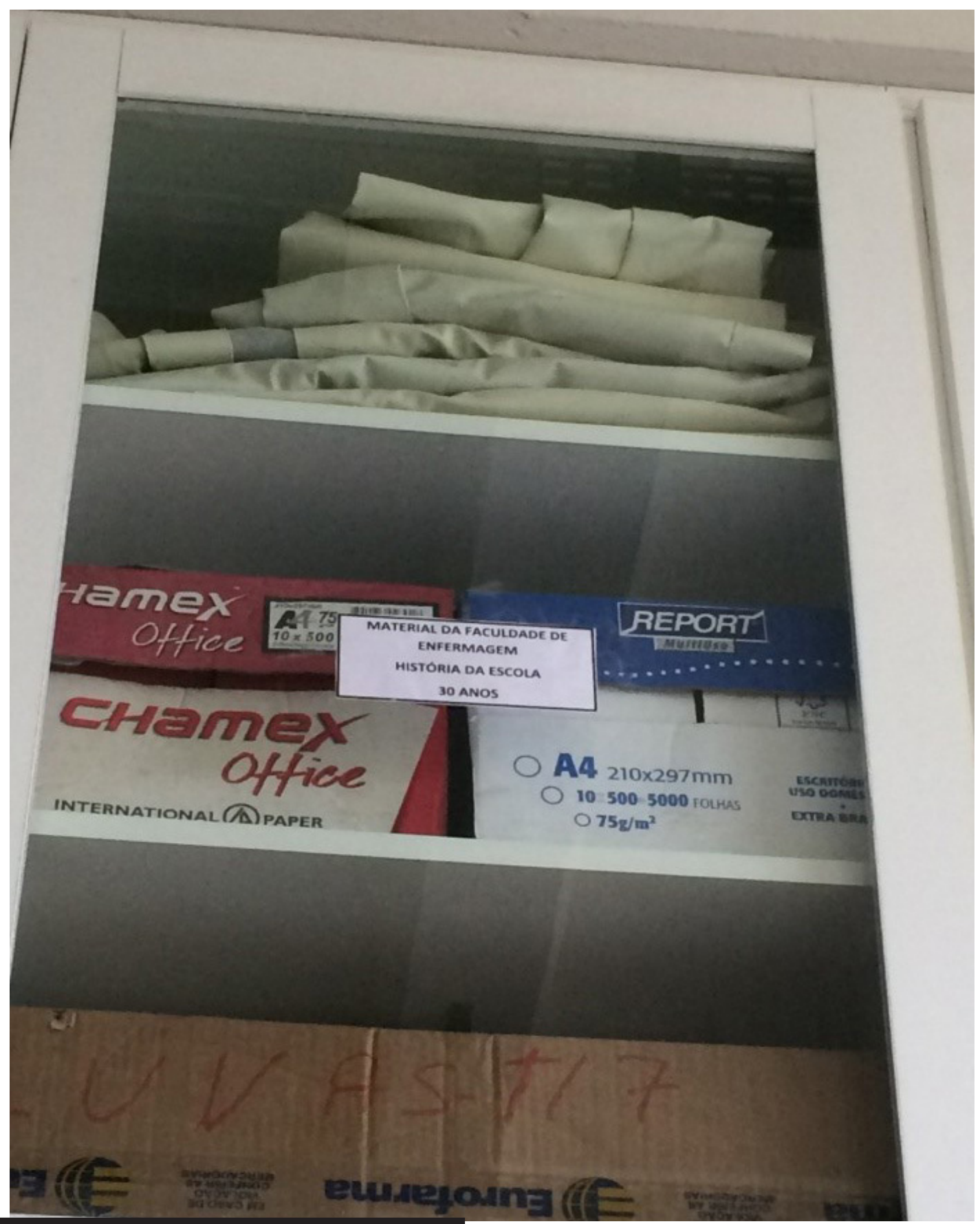

Imagem 2 - Armário contendo documentos -

nível 2. Fonte: Imagem produzida pelos autores,

2015. 
Esse foi considerado o segundo nível, pois, apesar de não estar ao alcance das mãos, está visível ao público que frequenta e pode ser identificado através das etiquetas indicativas do conteúdo das caixas, bem como da referência aos 30 anos da Faculdade de Enfermagem.

Já a terceira categoria, ou terceiro nível, conforme as imagens 03 e 04, é representada pelos objetos tridimensionais, localizados no depósito de um dos laboratórios. Nessa categoria, existem objetos de dimensões maiores, tal como os tambores de esterilização do material hospitalar, e antigos materiais para realização de procedimentos. São objetos de metal, que cumpriram sua função econômica e utilitária, e caíram em desuso, mas foram preservados pela instituição.

Afora isso, existem caixas contendo antigas embalagens de algodão e gaze, além do material de vidro para preparação de medicamentos. Esses objetos, por conseguinte, são mais sensíveis e vulneráveis a perdas e degradação, em função de sua constituição física.

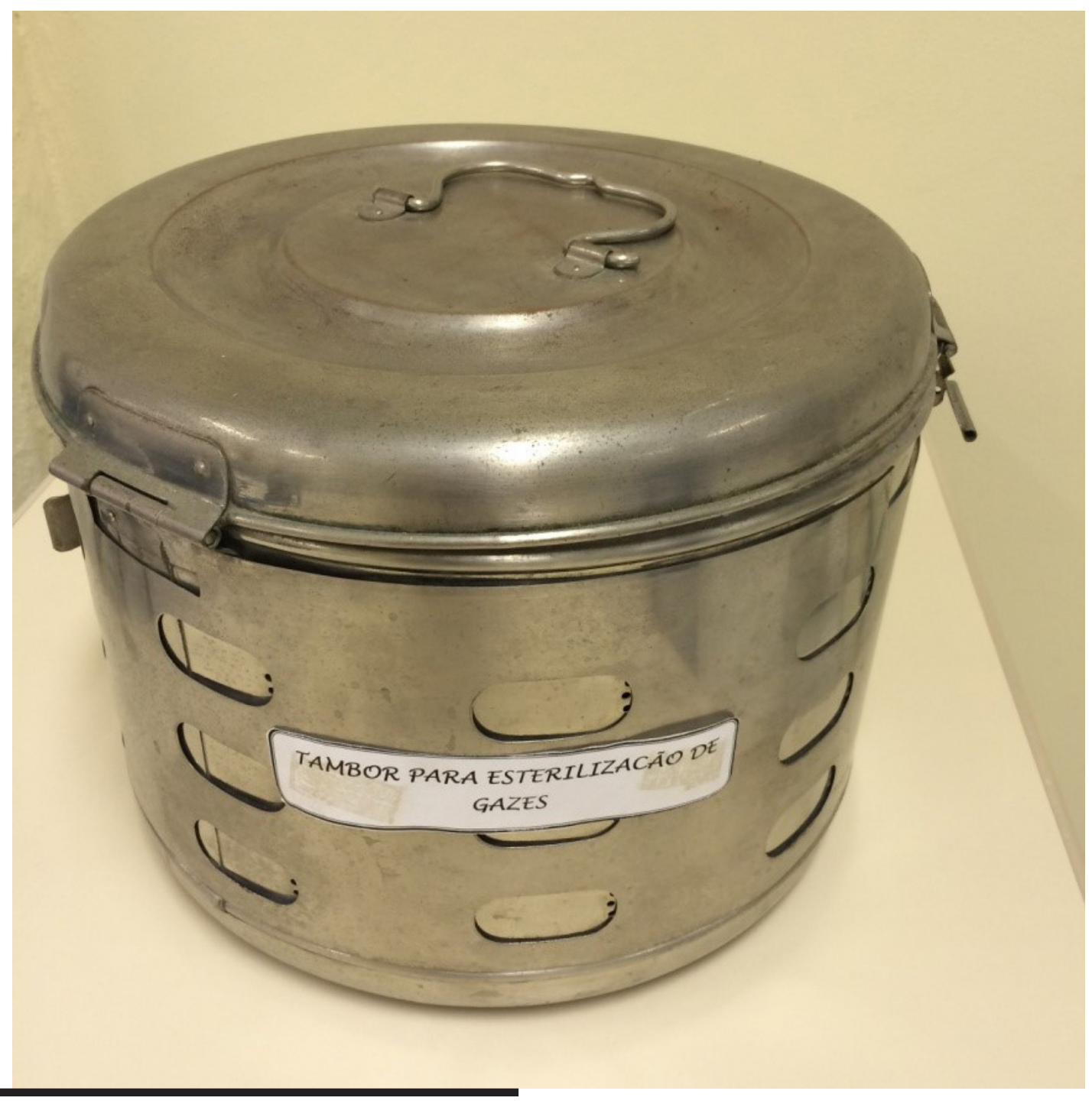

Imagem 3 - Objetos FEn nível 3. Fonte: Imagem produzida pelos autores, 2016. 

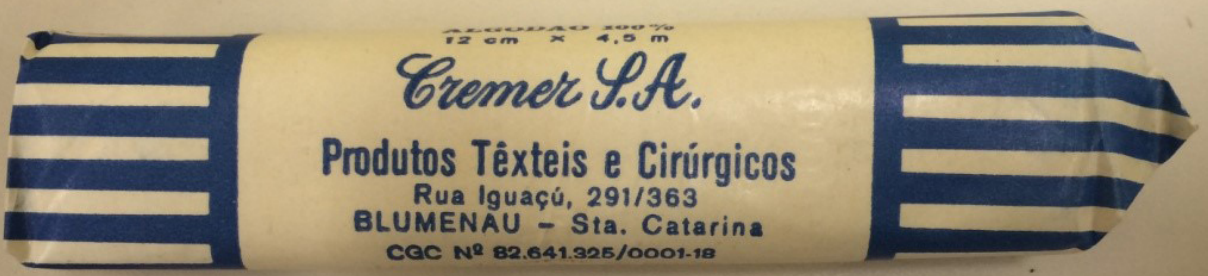

Imagem 4 - Objetos FEn nível 3. Fonte: Imagem produzida pelos autores, 2016.

Ao verificar os três níveis de disposição dos objetos, algumas reflexões se tornam pertinentes. Percebe-se a intenção de preservá-lo, bem como às informações pesquisadas e coletadas, através da manutenção das etiquetas, por exemplo. Mas, para além disso, esses objetos acompanham a história funcional dessa unidade, relacionam-se com a vontade de memória da Faculdade e apresentam, através do ato de preservação, a potencialidade para a construção efetiva da memória e da identidade não só institucional, mas também científica das práticas relacionadas à enfermagem.

Para melhor compreender o processo de construção da memória e da identidade desse grupo, será necessário avançar no entendimento do processo da seleção e formação de sua coleção.

\section{2 - O ATO DE COLECIONAR E A CONSTRUÇÃO DA MEMÓRIA INSTITUCIO- NAL E CIENTÍFICA}

Para compreender melhor as noções que perpassam a seleção dos objetos, faz-se necessário relacionar conceitos relativos ao ato de colecionar, além de discorrer sobre as noções de patrimônio científico - categorias que atravessam diametralmente as coleções em exame. 
De acordo com a definição clássica de Pomian (1984, p. 52), o conceito de coleção se caracteriza como o "conjunto de objetos naturais ou artificiais, mantidos temporária ou definitivamente fora do circuito das atividades econômicas, sujeitos a uma proteção especial em local fechado preparado para esse fim, e exposto ao olhar do público”.

Entretanto, o autor lembra que o ato de colecionar se trata, na verdade, de um paradoxo, pois esses artefatos são conservados e submetidos à proteção especial, caracterizando-os como objetos preciosos, de modo que possuem valor de troca, mas não de uso. O autor destaca, ainda, que a coleção é "uma instituição universalmente difundida" (POMIAN, 1984, p. 68), dependendo de uma série de fatores, tais quais: o local onde foi concebido, o estado da sociedade, suas técnicas e modos de vida, além da capacidade de atribuir graus diferenciados de importância à comunicação entre o visível e o invisível através dos objetos.

Corroborando com isso, cabe citar Maria Cristina Bruno (2009, p. 14 - 15), segundo a qual as coisas ${ }^{7}$ não têm paz e, por isso, a partir de estudos relacionados à produção material:

[...] é porque as coisas não têm paz que a partir dos estudos desse universo de produção material é possível transgredir o seu contexto de visibilidade e penetrar nos cenários invisíveis, sensoriais e valorativos que extrapolam as barreiras impostas por análises pontuais ligadas, por exemplo, à medição dos objetos e à identificação da função dos artefatos, ou direcionadas para a organização de tipologias, ou ainda, esmagadas pela ênfase na proposição de hierarquias entre os conjuntos artefatuais.

Nesse sentido, Gonçalves (2007) considera que toda a coletividade dedica-se à atividade de colecionar. Embora os objetos não sejam colecionados visando aos mesmos objetivos em diferentes grupos, é através do deslocamento, essencialmente simbólico, dos objetos de uso cotidiano para coleções privadas, museus, ou mesmo para a categoria de patrimônio, que é possível observar "os processos sociais e simbólicos por meio dos quais esses objetos vêm a ser transformados ou transfigurados em ícones legitimadores de ideias, valores e identidades assumidas por diversos grupos e categorias sociais" (GONÇALVES, 2007, p. 24). O caráter transgressor das coleções, nesse sentido, sintetiza uma realidade que ultrapassa aquilo que pode ser deduzido da própria materialidade - cor, forma, tamanho, usos pregressos - e invade os aspectos imagéticos e simbólicos. Essa premissa nos leva a crer, portanto, que as coleções servem de moldura pela qual os sujeitos constroem as suas subjetividades - uma determinada imagem de si.

Portanto, é possível perceber que, no caso da FEn, a seleção dos objetos com os quais esse grupo se identifica - seja através do fazer profissional, seja através das práticas docentes e administrativas - forma a relação entre o visível e o invisível. Os objetos foram selecionados e deslocados de sua função original com a intenção de reavivar seu sentido simbólico retomando, dessa forma, as práticas da enfermagem e o percurso da consolidação do Curso.
${ }^{7}$ A autora inicia o artigo com a seguinte citação "As coisas têm peso, massa, volume, tamanho, tempo, forma, cor, posição, textura, duração densidade, cheiro, valor, consistência, profundidade, contorno, temperatura, função, aparência, preço, destino, idade, sentido. As coisas não têm paz" (Arnaldo Antunes, 1998). 
Deve-se considerar, ainda, que a percepção acerca da coleção, bem como a compreensão de determinado objeto enquanto vetor para a atribuição de significados simbólicos, depende da linguagem, da comunicação, para que haja a transposição entre o visível e o invisível de que trata Pomian (1984). Como já sinalizado, os objetos da cultura material devem ser vistos, compreendidos e lidos no interior de uma trama simbólica, em um mercado linguístico no qual, em um movimento pendular e intersubjetivo, as coisas também agem sobre nós. Em outros termos, construímos objetos na mesma medida em eles nos constroem - mas, para isso, é necessário estabelecer essa linguagem a que nos referimos. Gonçalves (2013), na apresentação do livro "Alma das Coisas", alerta que, apesar de os objetos estarem presentes nas nossas vidas, muitos de nós desaprendemos a falar a língua das coisas; apesar disso, "é provável que a alma das coisas ainda nos afete secretamente”. (GONÇALVES, 2013, p.8).

Ao retomar o ato de seleção dos objetos da Faculdade de Enfermagem, não se pode deixar de referenciar que, apesar desse movimento, a comunicação dos objetos com seu público poderia ocorrer de forma mais complexa, o que forma uma lacuna e, ao mesmo tempo, representa grande potencialidade para compreensão desses objetos como uma coleção e mesmo enquanto fonte de construção de uma memória forte.

Mendoza (2005) lembra que o ato de colecionar é mais complexo do que, apenas, conservar objetos, uma vez que é nutrido de intencionalidade. Esse ato caracteriza-se pela ação de selecioná-los a partir de planejamento e objetivos prévios e determinados. Assim, a autora considera ser possível classificar os objetos em três tipologias de coleção: coleção com finalidade de conhecimento ou coleção científica; coleção com finalidade axiológica (objetos culturalmente valiosos); e coleções com finalidades econômicas e políticas. Entretanto, a autora afirma que a inserção de determinado objeto em uma dessas categorias não o impede de pertencer, também, às demais. (MENDOZA, 2005, p. 220). No caso dos objetos preservados pela FEn, seria possível identificá-los, majoritariamente, com a primeira tipologia sugerida pela autora, ou seja, com finalidade de conhecimento ou científica. Destaca-se que há traços da iniciativa de preservar os objetos que a identificariam, ainda, com as demais tipologias de coleções propostas pela autora. Uma vez que Faculdade de Enfermagem é uma instituição de ensino superior, os objetos selecionados para representação de sua memória e identidade guardam relação, também, com coleções científicas.

Apesar da notável relação entre essas coleções e o desenvolvimento da ciência, elas encontram-se, via de regra, relegadas a um segundo plano. Assim, cabe destacar a existência de algumas questões que dificultam seu reconhecimento e valorização. Entre elas destacam-se, de acordo com Lourenço (2009), o fato de não existir consenso acerca do que seria patrimônio científico. Entretanto, Marcus Granato (2009, p. 79) considera como: 
o conhecimento científico e tecnológico produzido pelo homem, além de todos aqueles objetos (inclusive documentos em suporte papel), coleções arqueológicas, etnográficas e espécimes das coleções biológicas que são testemunhos dos processos científicos e do desenvolvimento tecnológico. Também se incluem nesse grande conjunto as construções arquitetônicas produzidas com a funcionalidade de atender às necessidades desses processos e desenvolvimentos.

Os objetos da ciência e tecnologia constituem-se importantes registros materiais e imateriais representados por seus suportes (como em teses ou dissertações, fotografias, descrição de relatos etc.), além de fontes de documentação e de pesquisa, objetivando a compreensão dos processos históricos nos quais foram concebidos.

Entretanto, conforme Marta Lourenço (2009), cerca de 90\% do patrimônio da ciência encontra-se em locais que não possuem vocação, missão, orçamento, pessoal qualificado ou mesmo a compreensão da importância da valorização dessa tipologia de cultura material. "Este patrimônio, do ponto de vista da tutela, encontra-se órfão, em situação vulnerável, de abandono, sujeito à arbitrariedade e em risco de danos irreversíveis e mesmo de perda irremediável.”(LOURENÇO, 2009, p. 47) Destaca-se, nesse sentido, o fato do patrimônio da ciência ser pouco valorizado por cientistas e historiadores das ciências.

Partindo desse pressuposto, deve-se considerar que o material selecionado pelas professoras e alunas da FEn, para representar sua memória, caracteriza-se como a constituição do seu patrimônio, apresentando potencial para instigar o interesse dos construtores do presente, seja do corpo docente, ou discente. Para tanto, destaca-se a importância da comunicação entre as partes envolvidas nesse processo.

Percebe-se, portanto, que a seleção dos objetos demostra importante potencialidade para a construção da memória e da identidade do grupo, que pode ser alavancada pelo processo de comunicação, demonstrando o processo de aquisição e atribuindo valor ao patrimônio preservado.

\section{CONCLUSÃO}

Ao longo deste artigo, buscou-se analisar a relação da Faculdade de Enfermagem da UFPel com sua cultura material e a forma como pode refletir na construção de sua memória e identidade, institucional, profissional e mesmo científica.

A análise e seleção dos objetos, em uma coleção, não ocorre de forma neutra, ao contrário, é sempre imbuída de intencionalidade. Memória e esquecimento andam sempre juntos e, dessa forma, a eleição do que se quer lembrar ou esquecer é uma escolha social e política, assim como a escolha dos objetos caracterizados como os elementos de construção da memória e da identidade para determinado grupo social. 
Partindo desse pressuposto, considera-se que o material selecionado pelas professoras e alunas da FEn, para representar sua memória, caracteriza-se como a constituição do seu patrimônio, apresentando potencial para instigar o interesse dos construtores do presente, seja das professoras, seja das alunas.

Sobre o desejo de preservar os objetos, foi possível perceber que, embora inicialmente tenha partido de uma convicção individual, o grupo entendeu a importância de refletir acerca da sua trajetória histórica e os elegeu para cumprir tal finalidade, apresentam diversas potencialidades. Aqui buscou-se perceber o caminho percorrido entre as comemorações e seus desdobramentos, representados pela salvaguarda (ainda que em alguns casos inadequada) dos objetos pesquisados, uma vez que essa não é atividade fim dessa unidade.

Sendo assim, é possível compreender, no caso da Faculdade de Enfermagem, que a busca pela construção da memória e da identidade se refletiu através do desejo pela comemoração desse curso. Através da valorização de seus elementos aglutinadores, ou seja, de suas retóricas holistas, conforme conceito de Candau (2012), seria possível, inclusive, imaginar a construção de uma memória forte compartilhada por esse grupo.

\section{REFERÊNCIAS BIBLIOGRÁFICAS}

BRUNO, Maria Cristina. Estudos de Cultura material e coleções museológicas: avanços, retrocessos e desafios. In: Cultura Material e Patrimônio de Ciência e Tecnologia. Rio de Janeiro: Museu de Astronomia e Ciências afins - MAST, 2009.

CANDAU, Joel. Memória e Identidade. São Paulo: Editora Contexto, 2012.

CANDAU, Joel. Bases Antropológicas e expressões mundanas na busca patrimonial: memória, tradição e identidade. In: Revista Memória em Rede, Pelotas: v.1, n.1., 2010 .

CASTELLS, Manuel. O Poder da Identidade. Lisboa: Fundação Calouste Gulbenkian, 2003.

GONÇALVES, José Reginaldo Santos. Teorias antropológicas e objetos materiais. In: Antropologia dos objetos: coleções, museus e patrimônios. Rio de Janeiro: Editora Garamond Ltda., 2007.

GONÇALVES, José Reginaldo Santos; BITAR, Nina Pinheiro e GUIMARÃES, Roberta Sampaio [orgs.]. A alma das coisas: patrimônio, materialidade e ressonância. Rio de Janeiro: Mauad X: Faperj, 2013. 
GRANATO, Marcus. Panorama sobre o Patrimônio da Ciência e Tecnologia no Brasil: Objetos de C\&T. In: GRANATO, Marcus; RANGEL, Marcio F. (Orgs.). Cultura Material e Patrimônio de Ciência e Tecnologia. Rio de Janeiro: Museu de Astronomia e Ciências afins - MAST, 2009.

KANTORSKI, Luciane. Entrevista concedida a autora através de meio digital (e-mail), em outubro de 2015.

LOURENÇO, Marta. O patrimônio da ciência: importância para a pesquisa. Revista Eletrônica do Programa de Pós-Graduação em Museologia e Patrimônio - Rio de Janeiro: Unirio |MAST, v.II, n.1, p.47-53, 2009.

NORA, Pierre. Entre Memória e História: a problemática dos lugares. Projeto História, n. 10, p. 7-28, 1993.

PÓS-GRADUAÇÃO EM ENFERMAGEM E OBSTETRÍCIA (Pelotas, Rio Grande do Sul). Cursos e Faculdades. Disponível em < http://www.cursosefaculdades.com. br/pos-graduacao-em-enfermagem-e-obstetricia-rio-grande-do-sul-pelotas-ufpel-FO-18572>. Acesso em 03 de maio de 2015.

POLLAK, Michael. Memoria e Identidad social. In: Memoria, Olvido Silencio: La producción social de identidades frente a situaciones limite. La Plata - Buenos Aires: Ediciones Al Margen, 2006.

RUEDA, Valéria, FREITAS, Aline de, VALLS, Valéria Martin. Memória Institucional: Revisão de literatura. Revista CRB-8 Digital, São Paulo: v. 4, n. 1, 2011.

SILVA, Helenice Rodrigues da. "Rememoração"/Comemoração: as utilizações sociais da memória. Revista Brasileia de História. São Paulo: v. 22, n, 44, p. 425-438, 2002. 